\title{
Long-term trends in fish recruitment in the north-east Atlantic related to climate change
}

\author{
Thomas Brunel And Jean Boucher \\ Institut Français de Recherche pour l'Exploitation de la Mer( IFREMER), BP 70, 29280, Plouzané, \\ France \\ *Correspondence. e-mail: thomas.brunel@libertysurf.fr \\ phone: $\quad+33(0) 298224368$ \\ fax: $\quad+33(0) 298224653$
}

\begin{abstract}
:
This study investigates the temporal correspondence between the main patterns of recruitment variations among north-east Atlantic exploited fish populations and large-scale climate and temperature indices. It is of primary importance to know what changes in fish stock productivity can be expected in response to climate change, to design appropriate management strategies. The dominant patterns of recruitment variation were extracted using a standardized principal component analysis (PCA). The first principal component (PC) was a long-term decline, with a stepwise change occurring in 1987. A majority of Baltic Sea, North Sea, west of Scotland and Irish Sea populations, especially the gadoids, have followed this decreasing trend. On the contrary, some herring populations and the populations of boreal ecosystems have followed an opposite increasing trend. The dominant signal in north-east Atlantic sea surface temperature, also extracted by a PCA, was highly correlated with the increase in the Northern Hemisphere Temperature anomaly, which is considered to be an index of global warming. The first component of recruitment was inversely correlated with these changes in regional and global temperature. The second PC of recruitment was a decadal scale oscillation, which was not correlated with climate indicators. The analysis of correlations between population recruitment and local temperature also indicated that the dominant pattern of recruitment variation may be related to an effect of global warming. The influence of fishing on recruitment, via its effect on the spawning stock biomass (SSB), was also investigated by the analysis of correlations between fishing mortality, SSB and recruitment. Results indicate that fishing can be another factor explaining recruitment trends, probably acting in combination with the effect of climate, but cannot explain alone the patterns of recruitment variation found here.
\end{abstract}

Keywords: climate change ; comparative approach ; fishing impacts ; fish recruitment ; global warming ; North Atlantic 


\section{INTRODUCTION}

Global warming is discernible in temperature records since the beginning of the $20^{\text {th }}$ century, but is particularly noticeable for the last three decades (IPCC, 2001). According to climatic models, the warming of the past 30 years will become more pronounced during the $21^{\text {st }}$ century. It is hence of primary importance to understand the impacts of climate change on ecosystems, in order to design sustainable management practices for their exploitation (forestry, agriculture, fishery).

There is increasing evidence that global warming has an impact on marine life. Owing to the large amount of data collected by the Continuous Plankton Recorder, the effects of climate change were first evidenced for planktonic species. At the scale of the northern Atlantic, a northward shift of $10^{\circ}$ of latitude of the biogeographical boundaries of copepod species has occurred during the past four decades (Beaugrand et al., 2002). At a more local scale, changes in species abundances and diversity are observed in zooplankton communities. One well-known example of these changes is the decline in the North Sea of the sub-arctic copepod Calanus finmarchicus, an important food item for a number of fish species, and its replacement by Calanus helgolandicus, a temperate water species (Reid et al., 2003). For the phytoplankton, a strong increase of annual primary production was recorded at the end of the 1980s in the North Sea and oceanic regions in the west of the UK (Beaugrand and Reid, 2003). This enhanced primary production is related to a better phytoplankton growth and an extended growing season (Reid et al., 1998). Similar changes in phenology and production are also observed for terrestrial plants and are attributed to the effect of global warming and of a higher atmospheric $\mathrm{CO}_{2}$ concentration (Menzel and Fabian, 1999). These changes in the structure and composition of north Atlantic plankton communities are related to the effect of climate change on physical parameters of the sea, such as temperature (Richardson and Schoeman, 2004) or salinity (Möllmann et al., 2003), and on oceanic circulation (Reid et al., 2003).

The number of young fishes recruiting each year to fish stocks depends on stock size, which is affected by fishing, and on survival rate of individuals from eggs to juveniles (Cushing, 1996; Rothschild, 1986). Survival processes during recruitment are highly influenced by the physical and biological environment experienced by the early life stages (Hjort, 1914; Sinclair, 1988; Cushing, 1996). Climate change can potentially affect recruitment directly, through its effect on the physical environment, or indirectly, through bottom-up effects of the changes in zooplanktonic species (Stenseth et al., 2004). The influence of natural climatic variations on historical fish abundances fluctuations is illustrated by many examples (see e.g. Alheit and Hagen, 1997 and Klyashtorin, 2001). However, few studies have investigated the consequences of climatic changes induced by the recent global warming on fish recruitment. Changes in catches of North Sea horse mackerel (Trachurus trachurus) (Reid et al., 2001) and Atlantic salmon (Salmo salar) (Beaugrand and Reid, 2003) were related to changes in the physical environment and in the plankton community. Changes in climate may have also affected cod (Gadus morhua) growth off Labrador (Drinkwater, 2002) and cod recruitment in the North Sea (Beaugrand et al., 2003).

The question of the influence of climate on the dynamics of fish stocks is moreover crucial for fisheries management. Current management practices aim to adjust the level of catches to the level of recruits produced, and are limited by the difficulty to integrate the influence of environmental factors in recruitment predictions (Hall, 1999). Many environment-recruitment models have been developed, but they usually fail when retested several years later with more recent data (Myers, 1998). As they give a 
synthetic view of the local environmental factors that influence population dynamics, large-scale climatic indices often predict ecological processes better than local environmental variables (Hallett et al., 2004). It is hence important to analyse the possible links between fish recruitment and the large-scale climate indices that are representative of the changes in fish environment related to global warming.

The effect of climate change on fish recruitment is investigated here at the spatial scale of the Northeast Atlantic, including a great number of populations in a comparative approach. Adopting a macroecological point of view is often an efficient way to test general relationships in population ecology (Gaston and Blackburn, 2000). Such approaches have already been used in fisheries research to study the determinants of recruitment variability (Brander, 2000; Brunel and Boucher, 2006) or the stock and recruitment relationship (MacKenzie et al., 2003). The comparative approach adopted here aims to 1) identify coherent patterns of recruitment variation among Northeast Atlantic exploited fish populations, 2) investigate the temporal correspondence between these patterns in recruitment and climate indicators, and 3) examine the effect of fishing on stock size as another cause of recruitment variation. 


\section{MATERIAL AND METHODS}

\section{Abundance data}

Fish population data have been collected from the reports of ICES working groups on fish stock assessment (ICES, 2002a-d; 2003a-c) and were calculated by Virtual Population Analysis (VPA). These methods are based on equations that simulate yearto-year cohort survival and catch processes to reconstruct historical abundances and fishing mortality at age from catch at age data. The models are calibrated by abundance indices from scientific surveys and commercial fleets. The recruiting year-class is classically defined as the youngest year-class caught by the fishery, varying among populations between ages $0-4$. All time series were hence lagged by the number of years corresponding to the age of recruitment so that the dates in the series correspond to the year of birth of the year-class. There are some well-known sources of errors potentially affecting the accuracy of abundance estimates from VPA (Ulltang, 1977). These data are however considered to be the most accurate recruitment data (Hilborn and Walters, 1992) and are commonly used in analysis on recruitment variability (Planque and Fredou, 1999). For the recent years, however, the VPA estimates are less reliable. For this reason, the last two years of the series were removed.

The temporal window chosen for this analysis was the 1970-1998 period. This three decade period was the result of a trade-off between the length of time series needed to investigate long-term trends in recruitment and the number of populations for which data were available. The 40 populations considered in this work belong to nine species living in 10 fishing areas (Fig. 1). All recruitment time series were unbroken back to 1970, except for herring in the Irish Sea (beginning in 1971), sprat and herring in the Baltic Sea (1973), Norway pout (1974) and plaice in the Celtic Sea, English Channel and Kattegat and herring in the North-West of Scotland (1975).

\section{Climate data}

Climate, in its wider sense, refers to the state of the atmosphere, for instance in terms of air mass distribution (IPCC, 2001). Climate variability represents the variations of atmospheric characteristics around the average climatic state, and occurs via recurrent and persistent large-scale patterns of pressure and circulation anomalies. Over the North Atlantic region, the most prominent and recurrent pattern of atmospheric variability is associated with the North Atlantic Oscillation (NAO). The NAO is estimated from the difference between Azore high and Icelandic low pressure centres. The variations of the NAO influence winter weather over the North Atlantic (storm track, precipitation, strength of westerly winds), and hence have a strong impact on oceanic conditions (sea temperature and salinity, Gulf Stream intensity, wave height). The winter NAO index used here is based on the difference of normalized sea level pressure between Lisbon, Portugal, and Reykjavik, Iceland, for the winter months (Hurrell, 1995). Indices were obtained from the internet (http://www.cgd.ucar.edu/cas/jhurrell/Data).

The second climatic index used was the Atmospheric Circulation Index (ACI, Klyashtorin, 2001), which characterizes the dominant direction of air mass circulation in the northern hemisphere. The calculation of this index is based on a classification of atmospheric circulation in three basic types: meridional (C), western (W) or eastern (E). Daily circulation type is calculated from pressure charts over the Atlantic-Eurasian region. The recurrence of each circulation type (W, E and $\mathrm{C}$ ) during the year is 
expressed in number of days of occurrence, and yearly anomalies are computed for each circulation type as the difference between the annual recurrence and the long-term average. The zonal atmospheric circulation index (ACI WE) is then calculated as the cumulated sum of the yearly $\mathrm{W}+\mathrm{E}$ anomalies. As the annual sum of $\mathrm{W}, \mathrm{E}$ and $\mathrm{C}$ anomalies will add to zero, the meridional circulation index (ACI C) is then equal to ACI WE. This index being a cumulated sum, a period of years of increasing (decreasing) ACI WE corresponds to the dominance of zonal (meridional) atmospheric circulation - or zonal (meridional) “epoch”.

The accumulation of anthropogenic greenhouse gases in the atmosphere is responsible for the global increase in earth temperature (IPCC, 2001). This human induced external forcing of the climatic system is also responsible for profound changes in the climate. A frequently used measure of global warming is the Northern Hemisphere Temperature anomaly (NHT, Jones and Moberg, 2003) which is computed as the anomaly in the annual mean of sea water and land air surface temperature over the northern hemisphere. The NHT anomalies data were provided by the web site http://www.cru.uea.ac.uk/cru/data/temperature/\#datter.

\section{Sea surface temperatures}

Climate variability can influence the marine environment by modifying at the same time the local forcing on the ocean and the oceanic circulation. The impact of climate change on the physical environment varies from place to place across the North Atlantic but can present a relative homogeneity at the regional scale (Hurrell and Dickson, 2004). To understand how homogenous or heterogeneous the response of the ocean to climate may be, and to make the link between climate and fish recruitment, variations in sea surface temperature (SST) in the Northeast Atlantic were investigated.

The SST data were provided by the International Comprehensive OceanAtmosphere Data Set (ICOADS : http://www.cdc.noaa.gov/coads/), for the Northeast Atlantic region, for the period from 1965 to 1997. This dataset is a compilation of observational records from ships and buoys averaged monthly in $2^{\circ}$ latitude by $2^{\circ}$ longitude boxes. Boxes which had two or more months without data were excluded from the analysis. Time series of annual mean temperature were then computed in each of the remaining 353 boxes.

\section{Principal Component Analyses of recruitment and temperature data}

Two standardised Principal Component Analyses (PCA) were conduced to detect the dominant patterns of variation in the recruitment and SST datasets. PCA is a technique commonly used to summarise the variability of large datasets into a small number of orthogonal and possibly meaningful variables named principal components (PC). Each PC explains a percentage of the total variance of the dataset. The first PC is computed as the linear combination of the variables that explains the greatest amount of the total variability. The second PC explains the greatest amount of the remaining variability, and so on, until there are as much PCs as there are variables in the dataset. The first two or three PCs generally summarise most of the information of a dataset.

In the present case, PCA was applied to the recruitment dataset (population recruitment as columns and years as rows), and to the SST dataset (geographical boxes as columns and years as rows). As variables in these PCA were time series, the PCs generated were also time series and represented the dominant patterns of variation in recruitment and in SST datasets. Because recruitment distribution is not normal but 
rather lognormal, recruitment data were log-transformed to stabilise variances before computation.

A loading vector is associated with each PC, giving the correlations between the PC and recruitment time series of each population (or SST time series in each geographical box). Populations (or geographical boxes) that have similar significant loadings on the first PCs therefore have similar temporal variations.

One of the key results from PCA is that the information summarised in the PCs represents the variability that is common among populations, and which is likely due to a common climatic influence (Mantua, 2004).

\section{Analysis of regional and local correlations between recruitment, temperature and climate}

To investigate the links between recruitment, sea surface temperature and climate at the regional scale of the Northeast Atlantic, Pearson correlation coefficients between the PCs of fish recruitment, climate indices and the PCs of SST were calculated. The link between SST variations and recruitment at the population scale was also analysed by computing correlation coefficients between log-recruitment and local temperature. The local temperature used was defined, as in Planque and Fredou (1999), by the mean temperature during spring months (February to June) for the ICOADS boxes included in the ICES area where the population is assessed.

Fish recruitment and environmental time series are often autocorrelated, i.e. the value of one year depends on the value in previous years. Because these autocorrelations violate the assumption of serial independence required for hypothesis tests, tests of significance of correlation coefficients can be biased due to overestimation of the number of degrees of freedom (Pyper and Peterman, 1998). To cope with these autocorrelation effects in our correlation tests, the number of degrees of freedom was adjusted using the modified Chelton method as described in Pyper and Peterman (1998).

When multiple statistical tests are conducted at the same significance level $(\alpha)$, the probability of obtaining at least one significant result is greater than this significance level (Peres-Neto, 1999). Therefore, there is an increased probability of deciding that a correlation is significant when it is indeed purely random. A sequential Bonferroni correction applied with Hochberg's (1988) procedure was used to reduce the probability of assigning significance to non-significant correlations.

\section{Effect of fishing}

To test the hypothesis that changes in recruitment are a consequence of the effect of fishing on the spawning stock, the links between the time series of recruitment, spawning stock biomass (SSB) and fishing mortality (F) were investigated. The influence of fishing on stock size was examined through the analysis of correlations between SSB and F. The link between stock and recruitment was measured by correlations between SSB and recruitment time series. Correlations between SSB and recruitment time series lagged of a number of years corresponding to age at maturity of populations were also calculated to examine the dependence of stock size on recruitment of the previous years. 


\section{RESULTS}

\section{Long-term changes in fish recruitment}

The dominant trend of variation in recruitment was represented by the first PC of the PCA, which explained $22 \%$ of the total variability of the data. The score of the first PC (Fig 2a) was a long-term decline, characterised by a rapid switch from positive to negative values occurring in 1987. The second mode of recruitment variation (Fig 2b) explained $14 \%$ of the variability and showed an increasing trend from the early 1970s to the mid 1980s and a decline since then. The other PCs explained each less than $8 \%$ of the variability and were hence less representative.

High loadings ( $|r|>0.5$ ) on the first PC occurred for 16 populations, and another 13 populations were loaded at $|r|$ between 0.3 and 0.5 (Table 1). Most of high correlations with the first PC (14 of the 16) were positive, indicating that the first PC was mostly due to a general decline in the recruitment of fish populations. The largest loadings on the first PC were found for the gadoid populations located in the Baltic Sea, Kattegat, North Sea, Irish Sea and West of Scotland. This was the case in particular for cod, for which six populations of these regions were positively correlated to the first PC ( $r$ ranging from 0.59 to 0.88 ). Among other gadoid species, strong loadings were also found for whiting (Merlangius merlangus) in the North Sea $(r=0.70)$ and in the West of Scotland ( $r=0.64)$, North Sea haddock (Melanogrammus aeglefinus) $(r=0.57)$ and Norway pout (Trisopterus esmarkii) $(r=0.50)$. Recruitment of cod in the Northeast Arctic was negatively correlated to the first PC which indicated that this population had an increasing recruitment trend, opposed to the score of the first PC. The other populations of cod (in the Celtic Sea, Iceland and Faroe Islands) and haddock (Faroe Islands, West of Scotland and Northeast Arctic) had weaker or negligible loadings on the first PC. Among herring (Clupea harengus) populations, the number of negative and positive loadings on the first PC was more balanced than for gadoid species. The highest positive correlations were found for the northwest of Scotland, Baltic Sea and Irish Sea populations, and the highest negative correlations were found in the Northeast Artic, Iceland, North Sea and Gulf of Riga. The other populations well correlated to the first PC were plaice (Pleuronectes platessa) in the North Sea, Celtic Sea and Irish Sea, and saithe (Pollachius virens) in Iceland.

Correlations with the second PC were, on average, weaker than with the first one (mean $|r|=0.42$ vs. mean $|r|=0.32$ ). There were 16 populations well correlated with this second PC ( $|r|>0.4)$. Among these populations, some were not correlated with the first PC (e.g. cod in the Celtic Sea, plaice in the English Channel or herring in the southwest of Scotland). The second PC hence represented their dominant mode of variation. Other populations correlated to the second PC were positively correlated to the first PC (e.g. cod in Irish Sea, West of Scotland, Western Baltic Sea, Kattegat or herring in the North Sea and in the northwest of Scotland). Their recruitment trend was represented by the first PC, but with a switch occurring before or after 1987, according to the sign of the correlation with the second PC.

Finally, there were 10 populations weakly loaded on both PCs. Recruitment of these populations had varied independently from the two main patterns described by the PCs. This was the case for all sole (Solea solea) populations, as well as for some gadoid populations in Iceland and the Faroe Islands. 


\section{Changes in climate and sea temperature}

Variations of the three climate indices are presented on Fig 3. Changes in the zonal atmospheric circulation index (Fig 3a) were characterised by the alternation of periods of constant increase, from 1900 to 1940, and from 1970 until the present, delimiting zonal circulation epochs, and of a period of decrease, from 1940 to 1970, corresponding to a meridional circulation epoch.

There was relatively little change in the NHT from 1886 to about 1910 (Fig. 3b). Since then, a warming of the northern hemisphere is evident. A first period of increasing temperature occurred during the zonal circulation epoch, from the early 1920s to about 1945. The following meridional circulation epoch, from the 1950s to the middle of the 1970s, corresponded to a slight decrease of the NHT. During the last three decades of zonal circulation, the NHT anomalies have exhibited a strong warming trend.

Variations of the winter NAO index (Fig. 3c) were dominated by interannual variability. There were also considerable long-term variations at the interdecadal time scale, represented by periods of persistent high (from 1900 to 1930, from 1980 to present) or low (1960 to 1975) NAO index.

The period studied here - from 1970 to 1998 - corresponded to a zonal circulation epoch during which the NHT was generally increasing. The NAO index was characterised by a long-term increase, modulated by oscillations, but was dominated by high frequency variations.

The dominant signal in SST variations (first PC, 26\%) was very similar to the signal of the global warming (Fig. 4a and Table 2). This signal was particularly perceptible in the southwestern oceanic region (correlations with local SST at $r>0.75$, map of the Fig. 4a). Temperature variations in all regions west of the UK and in the western North Sea were also well represented by this PC $(r>0.5)$. Weak negative correlations were found north of the Faroe Islands. The second PC of SST variations (22\%, Fig. 4b) was significantly related to the NAO index (Table 2). Temperature variations were highly related to this PC $(r>0.75)$ in the eastern part of the North Sea, in the Western Baltic Sea, and along the coast of Norway (map on the Fig. 4b). Correlations greater than 0.5 were also found in the Baltic Sea, western and southern parts of the North Sea, eastern Norwegian Sea, and Barents Sea. Negative correlations between the second PC and local SST were found in the southwest of Iceland.

\section{Correlations between recruitment, climate and SST}

The first PC of recruitment variations was strongly negatively correlated to NHT anomalies ( $r=-0.79, p<0.05$, Table 2, Fig. 5) and to the first PC of SST variation $(r=$ $-0.72, p<0.01$ ). There was also a strong correspondence between the dominant trend of fish recruitment and the increasing trend of the ACI ( $r=-0.79$, non-significant). The second component of recruitment variations was negatively correlated to the second component of SST variations, but the relationship was not significant $(r=-0.50, p=$ 0.064).

An additional PCA was performed on recruitment time series for a subset of 20 populations for which data were available back to 1960. This PCA was conducted to evaluate whether the association between the dominant pattern of recruitment variation and the NHT anomalies stands on a longer time period. The first PC for the period 1960-1998 explained 23\% of the variability in recruitment and was correlated ( $r=0.95)$ with the first PC for the period 1970-1998. Recruitment was relatively stable during the 
1960s and even exhibited a slight increase. The correlation with the NHT was still high $(r=-0.71, p<0.05)$ for the period 1960-1998.

Correlations between log-recruitment and local SST are given in Table 1. Correlation was significant at $\alpha=0.01$ for two populations (cod in the Irish Sea and plaice in the English channel) and at $\alpha=0.05$ for four other populations (cod in the North Sea, herring in the Gulf of Riga, and plaice in the North Sea and Irish Sea). The highest positive correlations were found for populations of the northern areas (four populations of the Northeastern Arctic, sprat in the Baltic Sea and herring in the Gulf of Riga, but also sole in the Celtic Sea). Negative correlations were found for southern populations of cod (West of Scotland, North Sea, and Irish Sea) and all plaice populations (except the Kattegat one). The differences in correlation values were significantly linked with the loading of populations on the first PC of the PCA of recruitment variations ( $r=-0.62, p<0.001$, Fig. 6). Populations negatively influenced by temperature variations at the local scale were generally those for which recruitment has decreased (positive loading on the first PC), and vice versa.

\section{Effect of fishing}

The links between recruitment, SSB and F for the 10 populations which had highest loadings to the first PC of recruitment (sharpest decrease in recruitment) are represented on Fig. 7. The first column shows the time series of SSB and of F. The levels of the reference points for $\mathrm{F}$, when available, are represented by the horizontal lines : $\mathrm{F}_{\mathrm{pa}}$ is the precautionary approach level of $\mathrm{F}, \mathrm{F}_{\text {lim }}$ is the level of $\mathrm{F}$ above which stock extinction becomes highly probable. Most of the 10 populations have been overexploited during the last three decades, with $\mathrm{F}$ almost always above $\mathrm{F}_{\mathrm{pa}}$, and even above $\mathrm{F}_{\text {lim }}$ for cod in the North Sea, West of Scotland, Kattegat and Irish Sea. A decrease in SSB was observed for most of the populations, except for plaice and herring in the Irish Sea and cod in the western Baltic. This decline was often well correlated (though significant only in two cases) with the increase in $\mathrm{F}$, or corresponded to a prolonged period of high F, as for North Sea whiting.

Correlations between recruitment and SSB were significant only for cod in the Kattegat (Fig. 7, second column). For other six populations, recruitment was less strongly correlated to SSB, with $r$ ranging from 0.41 to 0.51 and $p>0.05$. Recruitment variations were even less correlated with SSB for three other populations (cod and plaice in the Irish Sea, whiting in the West of Scotland : $r<0.14, p>0.5$ ).

Correlations between SSB and recruitment with lags were significant for seven populations (Fig. 7, third column). Correlations with lag were stronger than correlation with no lag for all populations and for six populations, correlation coefficients with lag were between 0.3 and 0.6 higher than correlations with no lag. 


\section{DISCUSSION}

There are coherent low-frequency signals in recruitment variability in the North East Atlantic which are represented by two dominant modes of variation isolated by PCA. These modes explain one third of the total variability in 40 recruitment time series. These modes indicate that, in addition to short term (e.g. interannual) variability, recruitment has exhibited temporally coherent long-term changes among the Northeast Atlantic populations. The dominant signal in recruitment variations is significantly correlated with the warming of sea water which occurred in most areas of the Northeast Atlantic and which is related to global warming due to atmospheric greenhouse gas accumulation. As in all studies based on statistical correlations, the identification and analysis of the underlying mechanisms is needed to confirm causal relationships. The results found here, however, suggest that long-term changes in recruitment may be related to global warming.

Global warming interacts with natural climatic variability. It is obvious from Fig. 3 that the increasing trend of the NHT is modulated by the natural variability of the climatic system reflected by the ACI oscillations (Klyashtorin, 2001). Global warming also influences the functioning of the climatic system (IPCC, 2001), which modifies the natural patterns of climate variability, such as the NAO. The NAO index has exhibited a substantial low frequency variability during the last four decades (Hurrell and Van Loon, 1997), which corresponds to the recurrence of negative values during the 1960s, and to the sustained positive phase since the end of the 1980s. This behaviour of the NAO is unusual, compared to its long-term variations (Fig. 3c), and has been related to the effect of global warming on North Atlantic climate (Gillet et al., 2003). Such changes in the NAO have influenced hydrography and ocean circulation (Dickson and Meincke, 2003), planktonic species abundance and fish recruitment (Stenseth et al., 2004). The decreasing trend in fish recruitment in many populations is coincident with the increasing trend observed in the NAO since 1965. The link between the main pattern of recruitment variation and global warming may hence also reflect the influence of the climatic changes that occurred during the last three decades.

Recruitment trends are generally ascribed to the effect of fishing on parent stock (Cook et al., 1997; Hutchings and Myers, 1994) and to the influence of climate on recruitment (see references cited in introduction). The effects of these two factors are however confounded and the question of their relative importance in driving the variations of fish populations is controversial (see Schiermeier, 2004 and Worm and Myers, 2004). This relative importance probably varies between stocks, or for the same stock, over time (Rose, 2004).

Intensive exploitation is thought to be responsible for the general decline of predatory fish stocks in the North Atlantic (Christensen et al., 2003). Fishing mainly targets the adult stock, but can also have an influence on recruitment the depletion of the SSB. This effect of fishing implies the existence of a direct link between spawner abundance and subsequent recruitment. Despite it is one of the most important and older questions in fisheries science, the existence of this link is still the subject of debates (see Gilbert, 1997 and Myers, 1997). The dependence of recruitment on spawner abundance has been verified by non parametric (Myers and Barrowman, 1996) and meta-analytical (MacKenzie et al., 2003) methods. However, because the existing models of the stock and recruitment relationship generally have large amount of unexplained variation (Rothschild, 1986), the influence of stock size, and hence of fishing, on recruitment can not be properly measured. 
For the majority of the 10 populations of Fig. 7, the correlations between F, SSB and recruitment suggest that the depletion of the spawning stock by overfishing has played a major role in the decline of recruitment. However, for half of the populations of Fig. 7 (cod in the Eastern and Western Baltic Sea, cod and plaice in the Irish Sea, and whiting in the West of Scotland), the decline in recruitment occurred before the decrease in stock biomass. For these populations, weak year-classes appeared while stocks were still at high levels, which, during previous years, allowed the production of good recruitments. After few years of poor recruitments and heavy exploitation, the SSB subsequently begun to decline. This pattern is supported by the increase in correlation of spawning biomass to recruitment when the time series are lagged by the mean ages of maturity (Fig. 7), which shows that several years of recruitment eventually contribute to the spawning populations.

In the case of the populations negatively correlated to the first PC (time series not shown here), the increase in recruitment was also correlated to the increase of stock size. But for some populations (e.g. Northeast Arctic cod or North Sea herring), again, strong year-classes appeared before the stock begun to increase, which indicates that the increase in recruitment was probably due to an improvement of environmental conditions for recruitment.

There is little doubt that the decline in biomass of some fish stocks is largely due to an excessive level of fishing, and that the increase of others is facilitated by lower levels of fishing mortality. However, to what extent changes in recruitment could result from - or contribute to - these changes in stock size is far less clear. For many populations, the changes in recruitment may have been initiated by environmental changes, that have amplified the effect of increased or relaxed fishing pressure on stocks.

Climate change can affect fish recruitment through direct (abiotic environment) and indirect (biological interactions) effects (Stenseth et al., 2004). The effect of temperature on recruitment at the population scale was investigated here by the analysis of recruitment-local SST correlations. Populations for which the increase in local SST was unfavourable (negative correlation) had generally a decreasing recruitment trend (positive loading on the first PC), and conversely, populations positively correlated to local temperature were mainly negatively loaded on the first PC. This influence of temperature is especially clear for cod, with positive effect for populations inhabiting cold waters, and negative effect for populations inhabiting warm waters, and has already been shown for this species by other studies (Planque and Fredou, 1999; Brander, 2000). This pattern is moreover consistent with the observation of an increase in recruitment variability from the centre toward the edges of species range (Brunel and Boucher, 2006), which suggests that the effect of environmental factors on recruitment should be more important at the limits of species range. The correlations with SST variations at the local scale are hence coherent with the large-scale association found between the dominant mode of recruitment and global (NHT) and regional (first PC of SST) warming.

Changes in recruitment of some populations, however, can not be explained by the correlations with local temperature. Many other factors, such as salinity, turbulence, ocean circulation, sea ice coverage - all of which are likely to be affected by climate change - can also influence recruitment (Stenseth et al., 2004). For instance, recruitment failure of Eastern Baltic cod has been related to the limitation of egg development success by low salinity and oxygen content conditions. Such conditions occurred during a stagnation period in the Baltic Sea, with no major saline water inflow 
from the North Sea for about one decade, that resulted from particular climatic conditions (MacKenzie et al., 2000; Köster et al., 2003). Climate influence on currents can influence the patterns of advection of fish eggs and larvae to unfavourable areas, and also lead to changes in recruitment (Myers and Drinkwater, 1989; Sinclair, 1988). The decline in sardine and mackerel recruitment off Portugal may be related to an increased loss of eggs and larvae to offshore areas due to the accentuation of coastal upwelling intensity (Santos et al., 2001). Accentuation of the upwelling resulted from the increase of winter winds at the beginning of the 1990s which was caused by the persistence of high positive NAO values.

Climate change can also affect fish recruitment by modifying interspecies relationships. Mortality due to predation during the pre-recruit stages is suspected to have a substantial influence on recruitment (Bailey and Houde, 1989). Changes in predation due to a direct effect of temperature increase on predation rate or to environmentally-induced changes in predator abundance (Van Der Veer et al., 2000) can hence cause changes in recruitment level. In the Baltic Sea, for instance, the recent increase in winter temperature is responsible for sprat recruitment success, leading to an increase in the sprat stock (MacKenzie and Köster, 2004 and Table 1). This resulted in an increased predation mortality on cod eggs and larvae, which, in addition with the effect of the stagnation period, has contributed to the decrease in cod recruitment (Köster et al., 2003).

Planktonic species also play the role of mediator between climate change and fish populations (Möllmann et al., 2003). Such bottom-up effects have probably influenced the recruitment of cod (Beaugrand et al., 2003), herring (Corten and Lindley, 2003) or sprat populations (Köster et al., 2003).

The response of fish populations to climate change must be considered in the wider context of an ecosystem response, which involves the physical environment, but also interspecies relationships between fishes and the other biological components of the ecosystems (Stenseth et al., 2004). This response of ecosystems may not be linear, but can instead take the form of regime shifts (Scheffer and Carpenter, 2003) It has recently been shown that regime shifts have taken place simultaneously in the North Sea and Baltic Sea around the years 1987-88, leading to drastic changes in planktonic species abundance and diversity and in the recruitment of gadoid and clupeid species (Alheit et al., 2005). The analysis of Beaugrand and Reid (2003) also revealed rapid changes occurring during the 1980s in SST, planktonic species abundances and Atlantic salmon catches at the scale of the Northeastern Atlantic. In the present study, the stepwise change in the first PC of the PCA on recruitment indicates that the changes in recruitment were particularly pronounced around 1987 for many fish populations. This synchrony between the abrupt changes in fish recruitment and others profound modifications in the ecosystems provides an additional indication for a relationship between recruitment trends and the impact of climate change on marine ecosystems.

The relationship found here at the northeastern Atlantic scale, between the dominant trend in recruitment and large-scale climate indices stresses the need to take account of the influence of climate on recruitment to improve the management of fish stocks. This relationship, however, is too uncertain, from a management perspective, to be used to make predictions of population response to climate change. More comprehensive studies are needed to understand better the mechanisms by which climate affects the productivity of fish stocks. The question of the relative importance of the influence of fishing and climate in driving the variations of recruitment also requires 
further investigation. Nevertheless, some adjustments of the stock assessment methods can be proposed in order to begin to integrate climate influence. For instance, instead of using the geometric mean of the past 10 years as a prediction of recruitment, as it is usually made for medium-term stock projections, different recruitment levels or trends can be tested to simulate population trajectories under different climate scenarios (see e.g. MacKenzie and Köster, 2004). Furthermore, biological reference points - levels of stock biomass bellow which stock is endangered - are established from the historical stock - recruitment plots under the assumption that recruitment is not affected by environmental changes. According to the present study, this assumption is not valid, and methods for estimating reference points which integrate the effects of environmental changes on recruitment should be developed.

\section{ACKNOWLEDGMENTS}

The authors would like to thank F. Blanchard and M. Laurans for providing constructive comments on the manuscript. We are also grateful to D. Schoeman and two anonymous referees for their reviews that greatly improved the manuscript. 


\section{REFERENCES}

Alheit J. and Hagen E. (1997) Long-term climate forcing of European herring and sardine populations. Fish. Oceanogr. 6: 130-139.

Alheit J., Mollmann C., Dutz J., Kornilovs G., Löwe P., Mohrholz V. and Wasmund N. (2005) Synchronous ecological regime shifts in the central Baltic and the North Sea in the late 1980s. ICES J Mar Sci. 62: 1205-1215.

Bailey K.M. and Houde E.D. (1989) Predation on eggs and larvae of marine fishes and the recruitment problem. Adv. Mar. Biol. 25: 1-83.

Beaugrand G., Brander K.M., Lindley J.A., Souissi S. and Reid P.C. (2003) Plankton effect on cod recruitment in the north sea. Nature. 426: 661-664.

Beaugrand G. and Reid P.C. (2003) Long-term changes in phytoplankton, zooplankton and salmon related to climate. Global Change Biol. 9: 801-817.

Beaugrand G., Reid P.C., Ibanez F., Lindley J.A. and Edwards M. (2002) Reorganization of North Atlantic marine copepod biodiversity and climate. Science. 296: 1692-1694.

Brander K.M. (2000) Effects of environmental variability on growth and recruitment in cod (Gadus morhua) using a comparative approach. Oceanol. Acta. 23: 485-496.

Brunel T. and Boucher J. (2006) Pattern of recruitment variability in the geographical range of the exploited northeast Atlantic fish species. J. Sea Res. 55: 156-168.

Christensen V., Guenette S., Heymans J.J., Walters C.J., Watson R., Zeller D. and Pauly D. (2003) Hundred-year decline of North Atlantic predatory fishes. Fish Fish. 4: 1-24.

Cook R.M., Sinclair A. and Stefánsson G. (1997) Potential collapse of North Sea cod stocks. Nature. 385: 521-522.

Corten A. and Lindley J.A. (2003) The use of CPR data in fisheries research. Prog. Oceanogr. 58: 285-300.

Cushing D.H. (1996) Towards a science of recruitment in fish populations. Oldendorf: Ecology Institute, 175pp.

Dickson R.R. and Meincke J. (2003) The north Atlantic Oscillation and the ocean's response in the 1990s. ICES Mar. Sci. Symp. 219: 15-24.

Drinkwater K.F. (2002) A review of the role of climate variability in the decline of Northern cod. Am. Fish. Soc. Symp. 32: 113-130.

Gaston K.J. and Blackburn T.M. (2000) Pattern and process in macroecology. London: Blackwell, 377pp.

Gilbert D.J. (1997) Towards a new recruitment paradigm for fish stocks. Can. J. Fish. Aquat. Sci. 54: 969-977.

Gillet N.P., Graf H.F. and Osborn T.J. (2003) Climate change and the North Atlantic Oscillation. In: The North Atlantic Oscillation : climatic significance and environmental impact. J.W. Hurrell, Y. Kushnir, G. Ottersen and M. Visbeck (eds) Washington: American Geophysical Union, pp. 193-209.

Hall S.J. (1999) The effects of fishing on marine ecosystems and communities. Oxford: Blackwell Science, 296pp.

Hallett T.B., Coulson T., Pilkington J.G., Clutton-Brock T.H., Pemberton J.M. and Grenfell B.T. (2004) Why large-scale climate indices seem to predict ecological processes better than local weather. Nature. 430: 71-75.

Hilborn R. and Walters C.J. (1992) Quantitative fisheries stock assessment. Choice, dynamics and uncertainty. London: Chapman \& Hall, 570pp.

Hjort J. (1914) Fluctuations in the Great fisheries of northern Europe viewed in the light of biological research. Rapp. P.-v Réun. Cons. Int. Explor. mer. 20: 1-228.

Hochberg Y. (1988) A sharper Bonferroni procedure for multiple tests of significance. Biometrika. 75: 800-802. 
Hurrell J.W. (1995) Decadal trends in North Atlantic Oscillation : Regional temperatures and precipitation. Science. 269: 676-679.

Hurrell J.W. and Dickson R. (2004) Climate variability over the North Atlantic. In: Marine ecosystems and climate variations. N.C. Stenseth, G. Ottersen, J.W. Hurrell and A. Belgrano (eds) Oxford: Oxford University Press, pp. 15-31.

Hurrell J.W. and Van Loon H. (1997) Decadal variations in climate associated with the North Atlantic oscillation. Clim. Chang. 36: 301-326.

Hutchings J. and Myers R.A. (1994) What can be learned from the collapse of a renewable resource? Atlantic cod, Gadus morhua, of Newfoundland and Labrador. Can. J. Fish. Aquat. Sci. 51: 2126-2146.

ICES (2002a) Report of the Arctic Fisheries Working Group. ICES C.M. 2002/ACFM:18, 451pp.

ICES (2002b) Report of the Baltic fisheries assessment working group. ICES C.M. 2002/ACFM:17, 543pp.

ICES (2002c) Report of the Herring Assessment Working Group for the Area South of $62^{\circ} \mathrm{N}$. ICES C.M. 2002/ACFM:12, 418pp.

ICES (2002d) Report of the Northwestern Working Group. ICES C.M. 2002/ACFM:20, 405pp.

ICES (2003a) Report of the Working Group on the Assessment of Demersal Stocks in the North Sea and Skagerrak. ICES C.M. 2003/ACFM:02, 616pp.

ICES (2003b) Report of the Working Group on the Assessment of Northern Shelf Demersal Stocks. ICES C.M. 2003/ACFM:04, 625pp.

ICES (2003c) Report of the Working Group on the Assessment of Southern Shelf Demersal Stocks. ICES CM 2003/ACFM:03, 470pp.

IPCC (2001) Climate change 2001 : the scientific basis. Cambridge: Cambridge University Press, 881pp.

Jones P.D. and Moberg A. (2003) Hemispheric and large-scale surface air temperature variations: An extensive revision and an update to 2001. J. Clim. 16: 206-223.

Klyashtorin L.B. (2001) Climate change and long-term fluctuations of commercial catches. The possibility of forecasting. FAO Fisheries Technical Paper. No 410: 86pp.

Köster F.W., Möllmann C., Neuenfeldt S., Vinther M., St John M.A., Tomkiewicz J., Voss R., Hinrichsen H.H., Kraus G. and Schnack D. (2003) Fish stock development in the Central Baltic Sea (1976-2000) in relation to variability in the physical environment. ICES Mar. Sci. Symp. 219: 294-306.

MacKenzie B.R. and Köster F.W. (2004) Fish production and climate: sprat in the Baltic Sea. Ecology. 85: 784-794.

MacKenzie B.R., Hinrichsen H.H., Plikshs M., Wieland K. and Zezera A.S. (2000) Quantifying environmental heterogeneity: habitat size necessary for successful development of cod (Gadus morhua) eggs in the Baltic Sea. Mar. Ecol. Prog. Ser. 193: 143-156.

MacKenzie B.R., Myers R.A. and Bowen K.G. (2003) Spawner-Recruit relationship and fish stock carrying capacity in aquatic ecosystems. Mar. Ecol. Prog. Ser. 248: 209-220.

Mantua N. (2004) Methods for detecting regime shifts in large marine ecosystems: a review with approaches applied to North Pacific data. Prog. Oceanogr. 60: 165-182.

Menzel A. and Fabian P. (1999) Growing season extended in Europe. Nature. 397: 659.

Möllmann C., Kornilovs G., Fetter M., Koster F.W. and Hinrichsen H.-H. (2003) The marine copepod, Pseudocalanus elongatus, as a mediator between climate variability and fisheries in the Central Baltic Sea. Fish. Oceanogr. 12: 360-368.

Myers R.A. (1997) Comment and reanalysis: paradigms for recruitment studies. Can. J. Fish. Aquat. Sci. 54: 982-983.

Myers R.A. (1998) When do environment-recruitment correlations work? Rev. Fish. Biol. Fish. 8: 285-305. 
Myers R.A. and Barrowman N.J. (1996) Is fish recruitment related to spawner abundance? Fish. Bull. 94: 707-724.

Myers R.A. and Drinkwater K. (1989) The influence of Gulf Stream warm core rings on recruitment of fish in the northwest Atlantic. J. Mar. Res. 47: 635-656.

Peres-Neto P.R. (1999) How many statistical tests are to many? The problem of conducing multiple ecological inferences revisited. Mar. Ecol. Prog. Ser. 176: 303-306.

Planque B. and Fredou T. (1999) Temperature and the recruitment of Atlantic cod (Gadus morhua). Can. J. Fish. Aquat. Sci. 56: 2069-2077.

Pyper B.J. and Peterman R.M. (1998) Comparison of methods to account for autocorrelation in correlation analyses of fish data. Can. J. Fish. Aquat. Sci. 55: 2127-2140.

Reid P.C., Borges M.d.F. and Svendsen E. (2001) A regime shift in the North Sea circa 1988 linked to changes in the North Sea horse mackerel fishery. Fish. Res. 50: 163-171.

Reid P.C., Edwards M., Beaugrand G., Skogen M. and Stevens D. (2003) Periodic changes in the zooplankton of the North Sea during the twentieth century linked to oceanic inflow. Fish. Oceanogr. 12: 260-269.

Reid P.C., Edwards M., Hunt H.G. and Warner A.J. (1998) Phytoplankton change in the North Atlantic. Nature. 391: 546.

Richardson A.J. and Schoeman D.V. (2004) Climate impact on plankton ecosystems in the Northeast Atlantic. Science. 305: 1609-1612.

Rose G.A. (2004) Reconciling overfishing and climate change with stock dynamics of Atlantic cod (Gadus morhua) over 500 years. Can. J. Fish. Aquat. Sci. 61: 1553-1557.

Rothschild B.J. (1986) Dynamics of marine fish populations. Cambridge: Harvard university press, 269pp.

Santos A.M.P., Borges M.d.F. and Groom S. (2001) Sardine and horse mackerel recruitment and upwelling off Portugal. ICES. J. Mar. Sci. 58: 589-596.

Scheffer, M., and Carpenter, S.R. (2003) Catastrophic regime shifts in ecosystems : linking theory to observation. Trends Ecol. Evol. 18: 648-656.

Schiermeier Q. (2004) Climate findings let fishermen off the hook. Nature. 428: 4.

Sinclair M. (1988) Marine populations. An essay on population regulation and speciation. Seattle: Washington Sea Grant, 252pp.

Stenseth N.C., Ottersen G., Hurrell J.W. and Belgrano A. (2004) Marine Ecosystems and Climate Variation. Oxford : Oxford University Press, 256pp.

Ulltang O. (1977) Sources of errors in and limitations of virtual population analysis (cohort analysis). J. Cons. Int. Explor. Mer. 37: 249-260.

Van Der Veer H.W., Berghahn R., Miller J.M. and Rijnsdorp A.D. (2000) Recruitment in flatfish, with special emphasis on North Atlantic species : Progress made by the Flatfish Symposia. ICES. J. Mar. Sci. 57: 202-215.

Worm B. and Myers R.A. (2004) Managing fisheries in a changing climate. Nature. 429: 15. 
Table 1. Loadings of the populations on the first two PCs of the PCA performed on the 40 recruitment time series and correlations between population recruitment and local temperature (significance levels * : $\alpha=0.05 ; * *: \alpha=0.01$ )

\begin{tabular}{|c|c|c|c|}
\hline & $\begin{array}{l}\text { Loading on the } \\
\text { first PC }\end{array}$ & $\begin{array}{c}\text { Loading on the } \\
\text { second PC }\end{array}$ & $\begin{array}{c}\text { Recruitment-local } \\
\text { SST correlation }\end{array}$ \\
\hline \multicolumn{4}{|l|}{ Cod } \\
\hline Northeast Arctic & -0.44 & -0.24 & 0.51 \\
\hline Iceland & 0.21 & -0.37 & 0.16 \\
\hline Faroe Islands & 0.37 & -0.32 & 0.04 \\
\hline Eastern Baltic Sea & 0.88 & -0.23 & -0.34 \\
\hline W. Scotland & 0.73 & 0.41 & -0.35 \\
\hline Kattegat & 0.64 & -0.40 & -0.25 \\
\hline North Sea & 0.74 & 0.18 & $-0.52 *$ \\
\hline Western Baltic Sea & 0.59 & -0.43 & -0.17 \\
\hline Irish Sea & 0.61 & 0.47 & $-0.62 * *$ \\
\hline Celtic Sea & -0.21 & 0.76 & -0.08 \\
\hline \multicolumn{4}{|l|}{ Haddock } \\
\hline Northeast Arctic & -0.35 & -0.03 & 0.58 \\
\hline Faroe Islands & 0.26 & -0.31 & 0.08 \\
\hline W. Scotland & 0.32 & 0.21 & -0.27 \\
\hline North Sea & 0.57 & -0.03 & -0.08 \\
\hline \multicolumn{4}{|l|}{ Herring } \\
\hline Northeast Arctic & -0.53 & 0.40 & 0.34 \\
\hline Iceland & -0.49 & 0.52 & -0.08 \\
\hline Gulf of Riga & -0.55 & -0.15 & $0.51 *$ \\
\hline Central Baltic Sea & 0.52 & -0.07 & 0.19 \\
\hline W. Scotland (N.) & 0.44 & 0.48 & -0.24 \\
\hline North Sea & -0.44 & 0.55 & -0.04 \\
\hline W. Scotland (S.) & 0.10 & 0.48 & -0.12 \\
\hline Irish Sea & 0.64 & -0.36 & -0.01 \\
\hline Celtic Sea & -0.31 & 0.44 & -0.14 \\
\hline \multicolumn{4}{|l|}{ Norway Pout } \\
\hline North Sea & 0.50 & -0.06 & -0.19 \\
\hline \multicolumn{4}{|l|}{ Plaice } \\
\hline Kattegat & -0.27 & -0.43 & 0.07 \\
\hline North Sea & 0.41 & 0.58 & $-0.53^{*}$ \\
\hline Irish Sea & 0.71 & 0.35 & $-0.50^{*}$ \\
\hline English Channel & 0.33 & 0.73 & $-0.62 * *$ \\
\hline Celtic Sea & 0.50 & 0.63 & -0.41 \\
\hline \multicolumn{4}{|l|}{ Saithe } \\
\hline Northeast Arctic & -0.11 & -0.30 & 0.48 \\
\hline Iceland & 0.44 & 0.11 & 0.08 \\
\hline Faroe Islands & -0.30 & 0.48 & -0.31 \\
\hline North Sea \& W. Scotland & 0.14 & -0.23 & 0.16 \\
\hline \multicolumn{4}{|l|}{ Sole } \\
\hline North Sea & -0.20 & 0.17 & -0.20 \\
\hline
\end{tabular}




\begin{tabular}{lrrr} 
Irish Sea & 0.02 & 0.01 & 0.04 \\
English Channel & 0.28 & 0.34 & -0.10 \\
Celtic Sea & -0.25 & -0.07 & 0.35 \\
\hline \multicolumn{1}{c}{ Sprat } & & & \\
\hline Baltic Sea & -0.34 & -0.23 & 0.51 \\
\hline \multicolumn{1}{c}{ Whiting } & & & \\
\hline North Sea & 0.70 & -0.26 & -0.00 \\
W. Scotland & 0.64 & 0.04 & -0.27 \\
\hline
\end{tabular}


Table 2. Correlations between the PCs of fish recruitment, climate indices and the PCs of sea surface temperature (significance levels: * $: \alpha=0.05 ;{ }^{* *}: \alpha=0.01$ )

\begin{tabular}{lcccccc}
\hline & \multicolumn{2}{c}{ Fish recruitment } & & \multicolumn{3}{c}{ Climate } \\
\cline { 2 - 3 } \cline { 6 - 7 } & First PC & Second PC & & NHT & ACI & NAO \\
\hline Climate & $-0.79 *$ & 0.10 & & & & \\
NHT & -0.79 & 0.60 & & 0.77 & & \\
ACI & -0.37 & -0.11 & & 0.29 & 0.36 & \\
NAO & $-0.72 * *$ & -0.03 & & $0.69 * *$ & 0.47 & 0.27 \\
Sea temperature & -0.23 & -0.50 & & -0.02 & -0.07 & $0.56^{*}$ \\
First PC & Second PC & -0.02 &
\end{tabular}




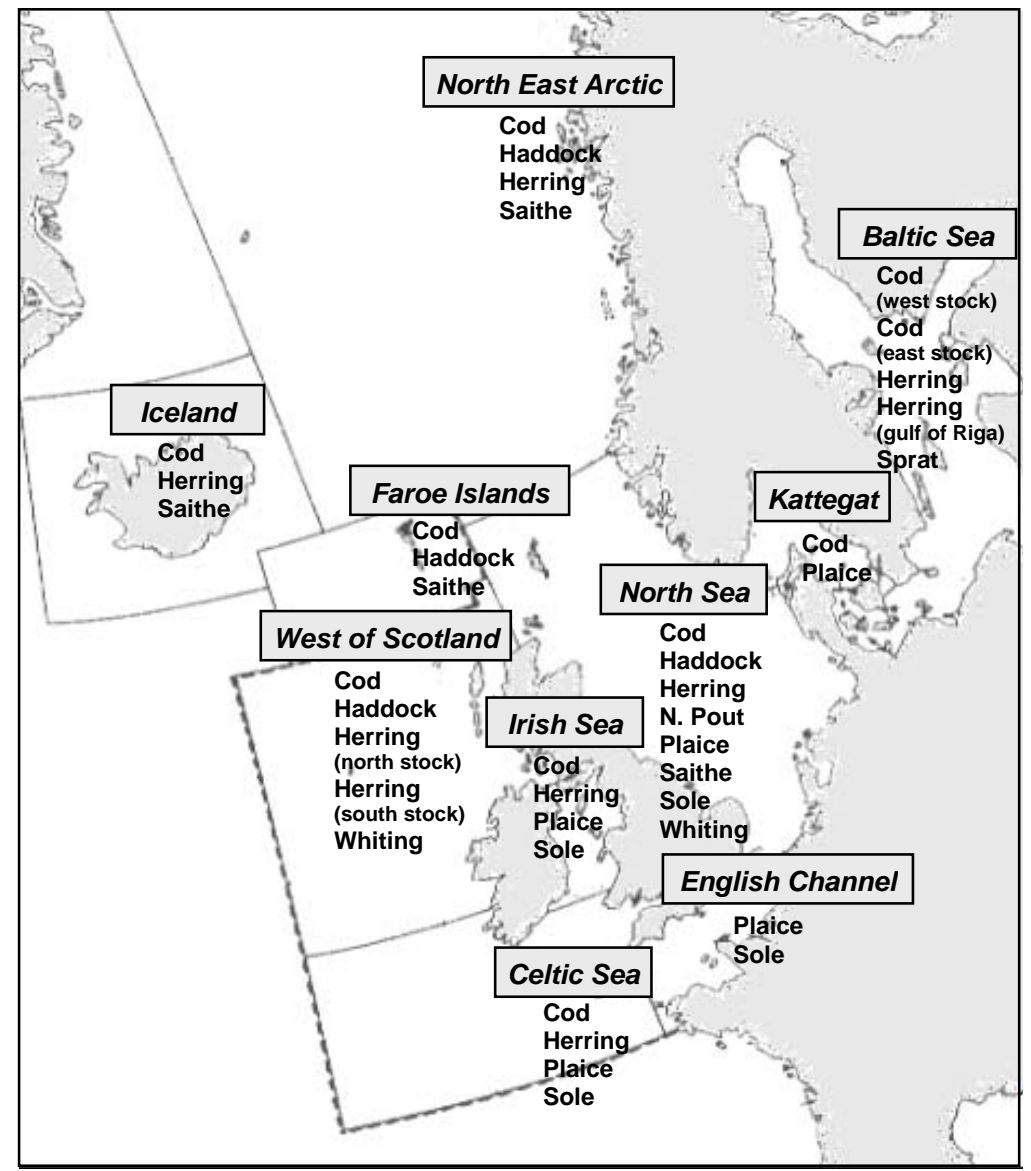

Figure 1. Map locating the 40 populations in the ten fishing areas. 

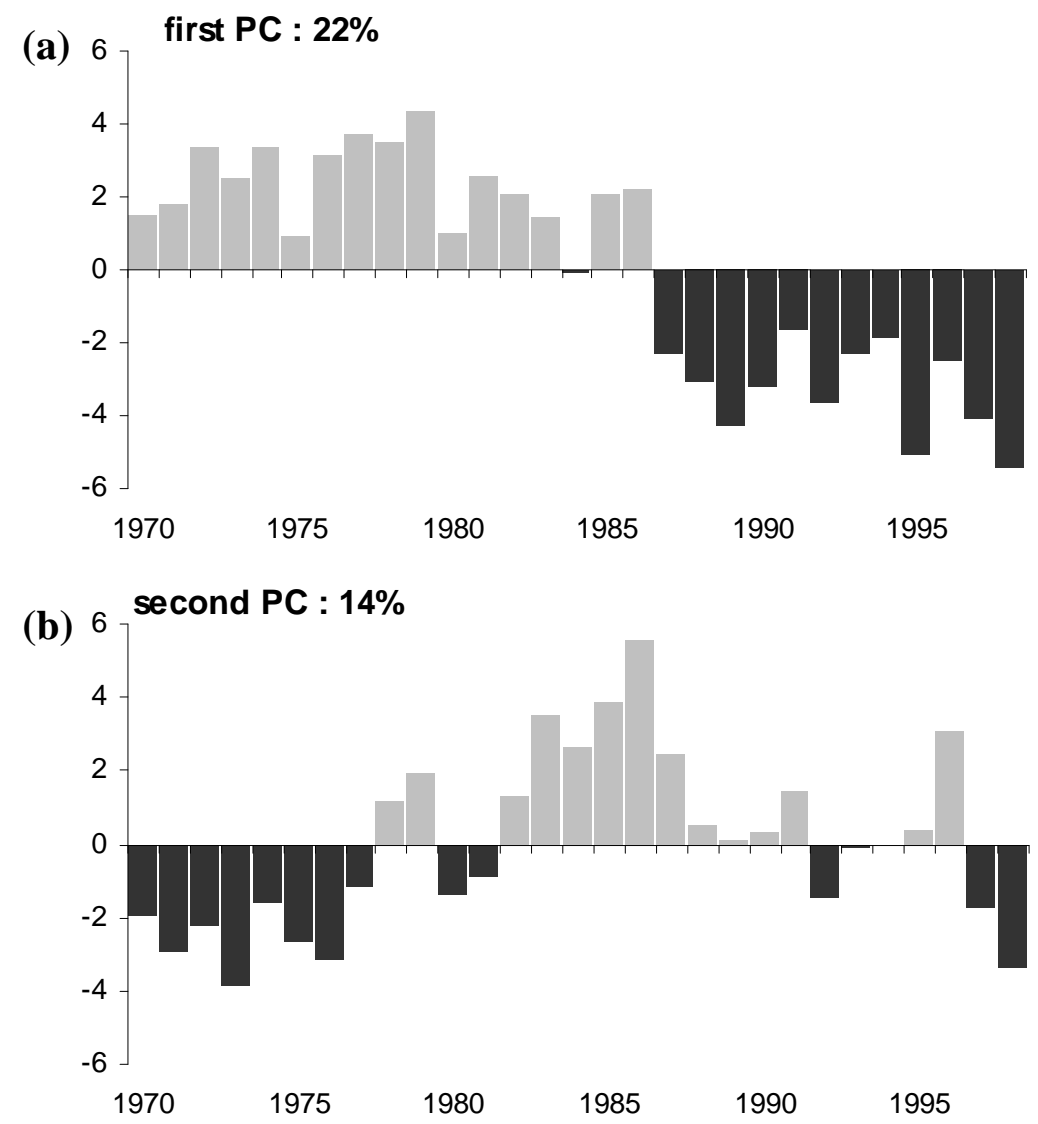

Figure 2. Dominant patterns of recruitment variations in the Northeast Atlantic. First (a) and second (b) PCs of the PCA performed on the recruitment time series of 40 populations. 
(a)

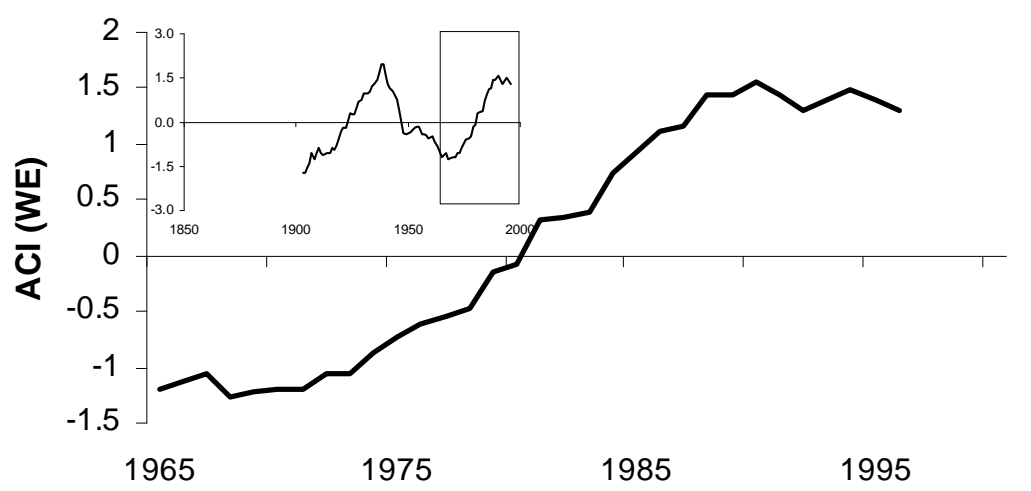

(b)

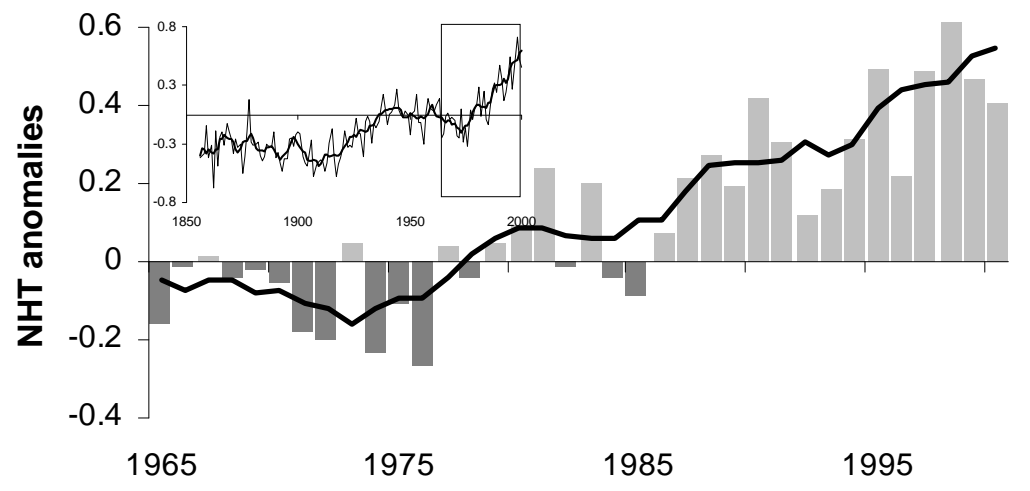

(c)

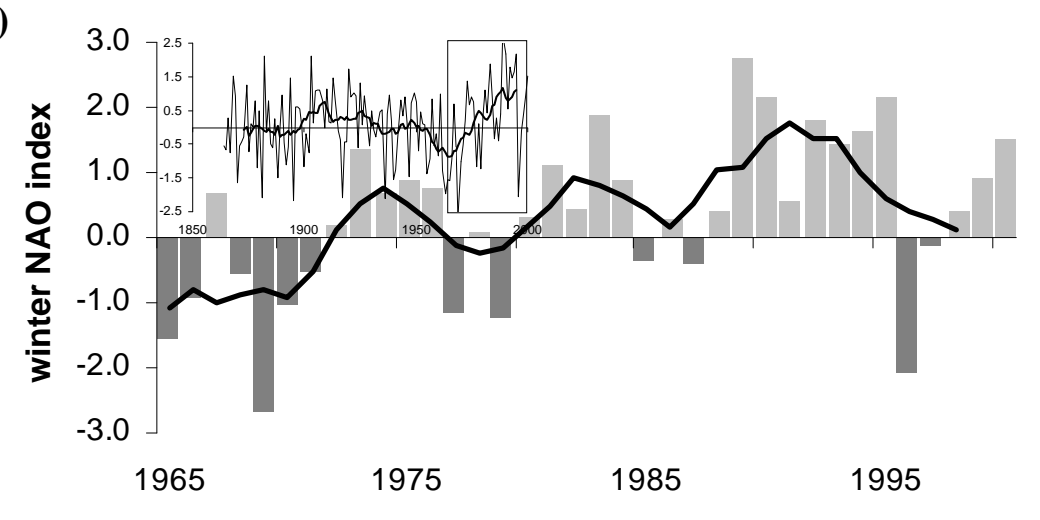

Figure 3. Variations of zonal Atmospheric Circulation Index (a), North Hemisphere Temperature anomalies (b), and winter North Atlantic Oscillation index (c) during the recent decades, and during the last 150 years (small graphs). 
(a) First PC (26\% )
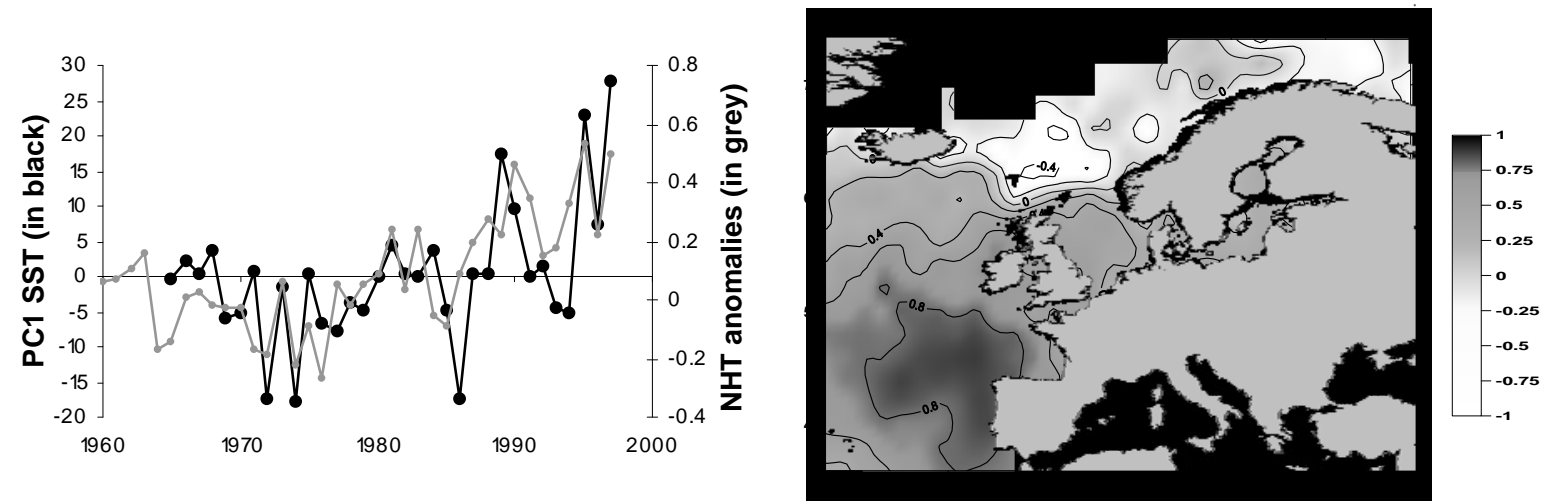

Map of the correlations between local SST and the first PC

(b) Second PC (22\%)
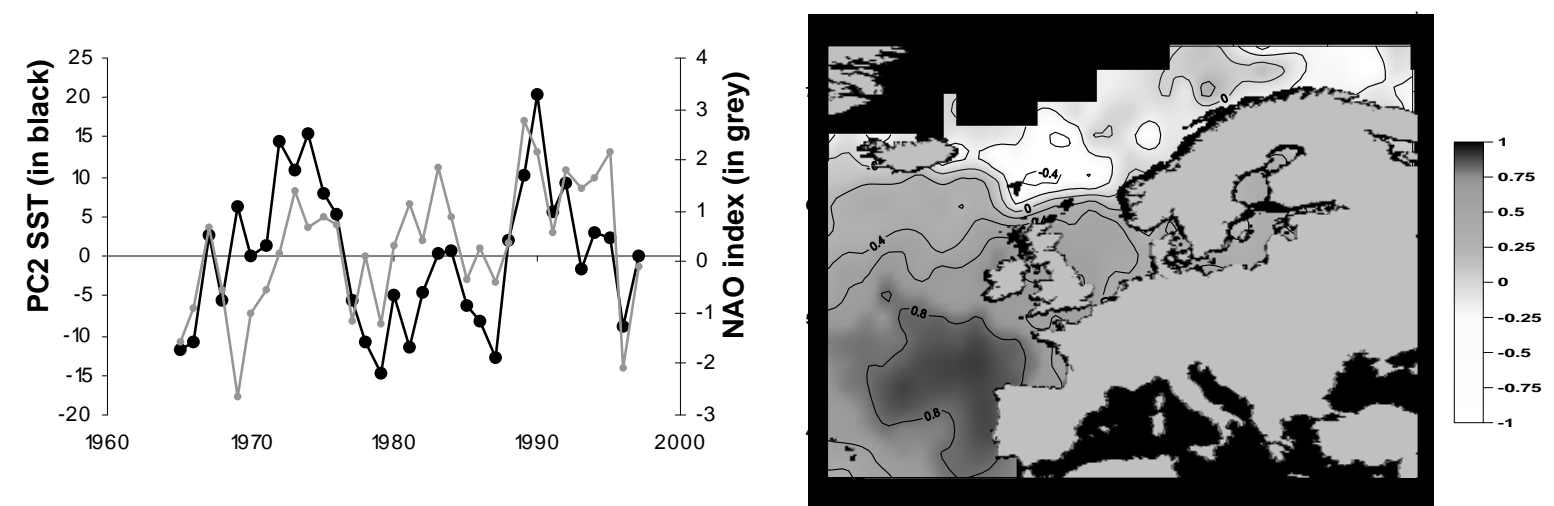

Map of the correlations between local SST and the second PC

Figure 4. Sea surface temperature variability in the Northeast Atlantic. First (a) and second (b) PCs of the PCA on SST compared with (a) NHT anomalies, and (b) NAO index. The maps give the correlations between the two PCs and local SST variations. 


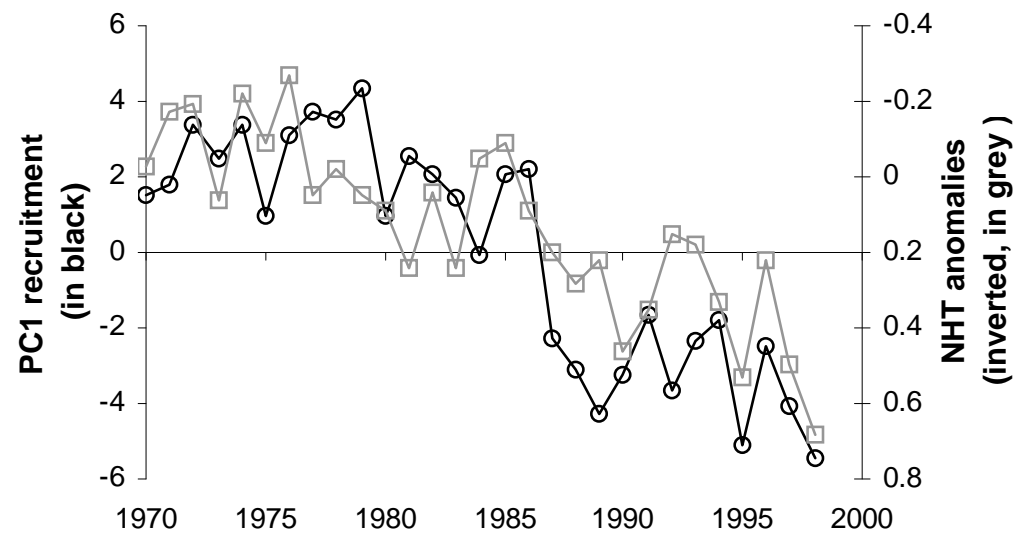

Figure 5. Relationship between the first PC of recruitment variations and NHT anomalies. 


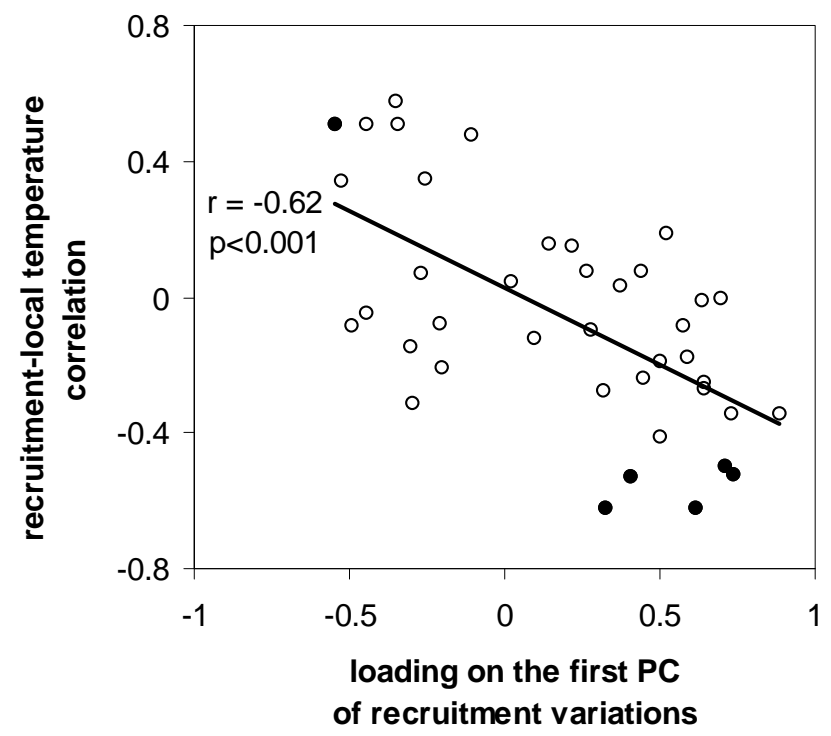

Figure 6. Relationship between recruitment-local temperature correlations and population loadings on the first PC of fish recruitment. Significant recruitment-temperature correlations are depicted by the black dots and non significant correlations by the empty circles. 


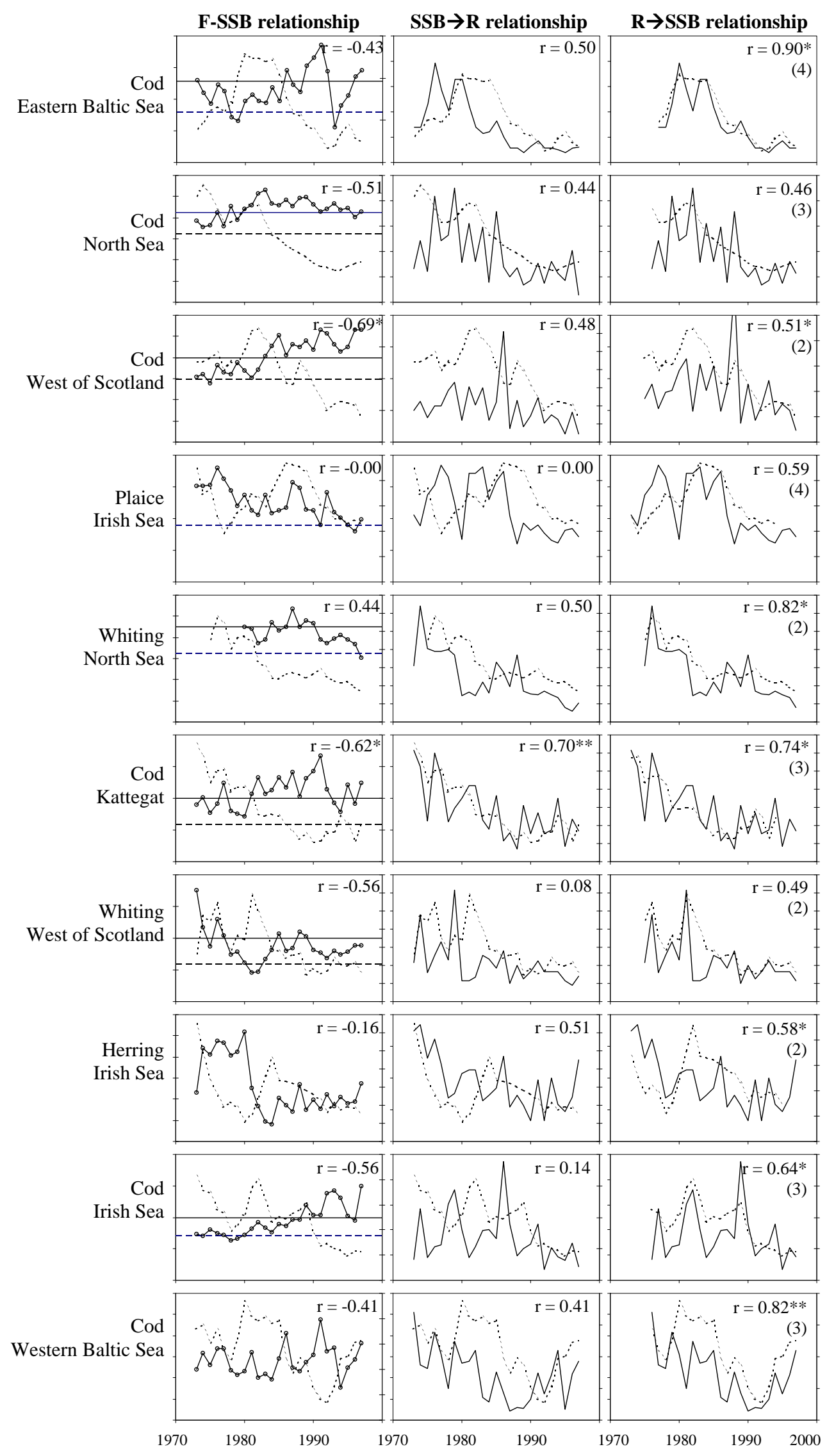

Figure 7. Relationships between fishing mortality (solid line with circles) and SSB (broken line) and between SSB and recruitment (solid line), for the 10 populations which had highest 
loadings to the first PC of recruitment. Horizontal lines in the first column indicate the levels of $F_{\text {pa }}$ (broken line) and $F_{\text {lim }}$ (solid line) (see in the text for details). Time series of recruitment and SSB in the third column are lagged of the number of years (in parenthesis) corresponding to the age at maturity of the population. Significance levels for the correlations $*: \alpha=0.05$; $* *: \alpha=0.01$. 